\title{
Opening a Marine Monument to Commercial Fishing Compromises Species Protections
}

\author{
Jessica V. Redfern' ${ }^{1 *}$ Kelly A. Kryc ${ }^{1,2}$, Lena Weiss ${ }^{1}$, Brooke C. Hodge', \\ Orfhlaith O'Brien ${ }^{1}$, Scott D. Kraus ${ }^{1}$, Ester Quintana-Rizzo ${ }^{3}$ and Peter J. Auster ${ }^{4,5}$ \\ ${ }^{1}$ Anderson Cabot Center for Ocean Life, New England Aquarium, Boston, MA, United States, ${ }^{2}$ Center for American \\ Progress, Washington, DC, United States, ${ }^{3}$ Department of Biology, Simmons University, Boston, MA, United States, ${ }^{4}$ Mystic \\ Aquarium, Mystic, CT, United States, ${ }^{5}$ Department of Marine Sciences, University of Connecticut, Groton, CT, United States
}

One of today's greatest conservation challenges is balancing policies, laws, and management strategies established to achieve economic goals that depend on extracting ocean resources with those established to conserve marine biodiversity. We use the Northeast Canyons and Seamounts Marine National Monument (NCSM) as a case study to explore the consequences of changing from a policy that prevents fishing to a fisheries management policy. We found that opening the NCSM to commercial fishing reduces species protections. Fishing with pelagic and bottom tending fixed gear exposes species inhabiting the sea surface and midwater regions to entanglement and bycatch risk. Fishing with bottom tending fixed gear also exposes deep-sea coral habitat to gear known to have detrimental impacts. The NCSM was designated as a marine national monument due to the area's unique ecological resources that are a subject of scientific interest. Our case study demonstrates that a fisheries management policy is insufficient to protect these ecological resources.

Keywords: marine protected area, marine reserve, biodiversity, fisheries management, marine national monument, Antiquities Act, Magnuson-Stevens Fishery Conservation and Management Act

\section{INTRODUCTION}

One of today's greatest conservation challenges is balancing policies, laws, and management strategies established to achieve economic goals that depend on extracting ocean resources (e.g., fish, oil, gas, and minerals) with those established to conserve marine biodiversity. Globally, this challenge is exemplified in the idealism of establishing marine protected areas (MPAs) to conserve biodiversity and the practicality of MPA effectiveness depending on their level of protection. Almost all MPAs (94\%) created globally before 2014 allow fishing activities (Costello and Ballantine, 2015), but studies have shown that fishing inside MPAs undermines biodiversity conservation (e.g., Dureuil et al., 2018). In the United States (US), this challenge is exemplified by the tension between policies that prevent versus allow fishing in MPAs. We use the Northeast Canyons and Seamounts Marine National Monument (NCSM) as a case study to explore the outcome of changing from a policy that prevents fishing to a fisheries management policy.

The United States Congress and the executive branch can designate lands and waters with varying degrees of protection to conserve their cultural, historical, natural, and scientific value. In September 2016, President Obama used the Antiquities Act to proclaim the Northeast Canyons and Seamounts (Figure 1A) a marine national monument due to the area's unique ecological resources that are a subject of scientific interest. The NCSM contains exemplars of offshore northwest Atlantic wildlife communities and habitats: seabirds, shelf-edge cetaceans, shelf fish, chemosynthetic communities, deep-shelf invertebrates, and deep-sea corals, sponges, fish, and 


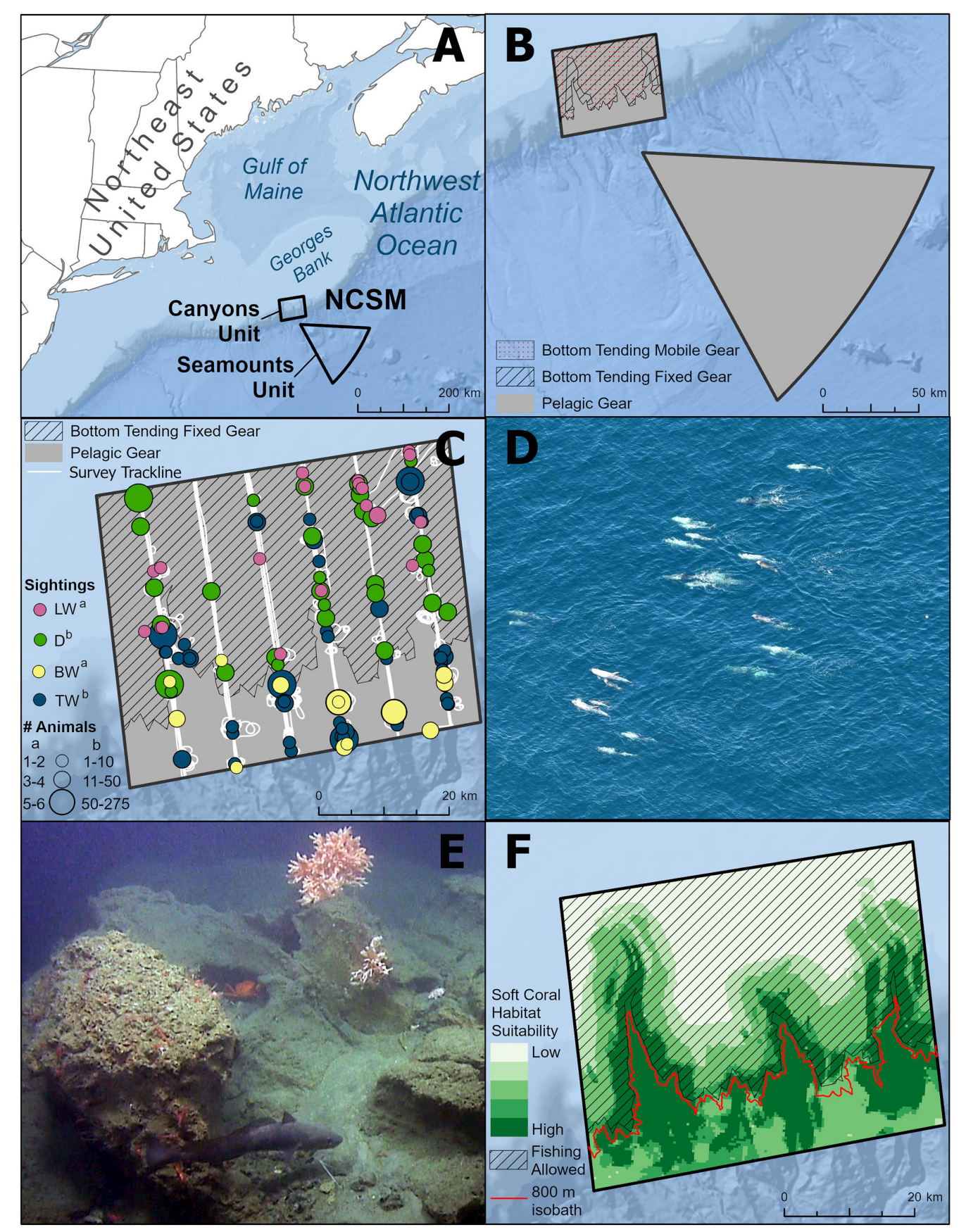

FIGURE 1 | (A) The Northeast Canyons and Seamounts Marine National Monument (NCSM). (B) Although the Magnuson-Stevens Fishery Conservation and Management Act (MSA) excludes bottom tending mobile and fixed gear from the deeper waters of the NCSM through the proposed Omnibus Deep-Sea Coral Amendment and the Lydonia and Oceanographer Canyons Gear Restricted Areas, a majority of the NCSM canyons unit is open to fishing with these gear types. The MSA also leaves the entire NCSM open to pelagic fishing. (C) Encounter rates for large whales (LW: blue, fin, humpback, and sei whales), which feed primarily on krill and small schooling fish, were higher in areas that are open to fishing with bottom tending fixed gear. The same was true for common, Atlantic spotted, and bottlenose dolphins (D), which are generalist feeders. However, striped dolphin (D), which are also generalist feeders, encounter rates were higher in areas protected from bottom tending fixed gear. Encounter rates were also higher in protected areas for species that feed primarily on squid, including beaked whales (BW: Cuvier's, Sowerby's, and True's beaked whales) and other toothed whales (TW: sperm whales, pilot whales, and Risso's dolphins). (D) A group of Risso's dolphins that includes mothers with calves. (E) Example of deep coral (Primnoa resedaeformis) and associated fauna, including red crab and shortfin squid (Chaceon quinquidens and Illex illecebrosus, respectively, both targets of fisheries), in cobble-boulder size sedimentary class habitat (depth 550 m, Oceanographer Canyon, 4 September 2019; image courtesy NOAA Okeanos Program). (F) Over a third of the region predicted to have the highest habitat suitability for soft corals (Kinlan et al., 2020) within the NCSM is unprotected by the proposed Omnibus Deep-Sea Coral Amendment (designated as fishing allowed in the map). The Omnibus does not exclude red crab fishing and the trap gear used to catch red crabs can impact deep-sea corals. If we consider red crab fishing, which can occur to $800 \mathrm{~m}$ depth, $46 \%$ of the highest suitable habitat is unprotected. 
soft sediment invertebrates (Auster et al., 2020). President Obama's proclamation excluded all commercial-scale extractive activities, including fishing and mineral extraction, with a 7year moratorium for existing offshore lobster and red crab fisheries. In response to objections raised by segments of the commercial fishing industry prior to and following designation, President Trump signed a proclamation in June 2020 that lifted the prohibition on commercial fishing in the NCSM and stated “...appropriately managed commercial fishing would not put the objects of scientific and historic interest that the monument protects at risk" (Trump, 2020). A law suit was immediately filed challenging the President's use of the Antiquities Act to reverse protections enacted by the original proclamation.

President Trump's proclamation effectively changed the NCSM from an area protected from commercial fishing under the Antiquities Act to allowing commercial fishing as managed under the Magnuson-Stevens Fishery Conservation and Management Act (MSA; the primary law governing marine fishing management in United States federal waters). The purposes of the MSA and the Antiquities Act are different and both have important roles to play in supporting healthy ocean ecosystems. The MSA seeks to prevent overfishing, rebuild overfished stocks, increase economic and social benefits, and ensure safe and sustainable seafood; the Antiquities Act seeks to protect places and ecosystems from the impacts of human activities. Our goal was not to assess the utility of the MSA as a fisheries management policy; instead, we evaluated how fishing activities allowed by the MSA would affect multiple species in the NCSM, which was designated as a marine national monument because of its high habitat and community diversity, high species richness, and ecological connectivity. This region is relatively undisturbed (Auster et al., 2020); however, the recent pattern of commercial fishing shifting to deeper waters (Morato et al., 2006) raises concerns for the NCSM. Many species that occur in this region are vulnerable to human activities because they have long recovery times and low resilience (e.g., deep-sea corals and sponges; apex predators, such as marine mammals). We assessed the changes in protections for marine mammals, seabirds, turtles, elasmobranchs, fish, and deep-sea corals under the MSA fisheries management plans. Our analyses used areas where different types of gear are allowed under the MSA, but did not include fishing effort.

\section{CHANGES IN SPECIES PROTECTIONS}

The NCSM comprises a continental margin unit that contains three deep-sea canyons (hereafter, canyons unit) and an offshore unit that contains four seamounts (hereafter, seamounts unit). We looked at changes in protections for the entire NCSM and for the canyons unit, which occurs closer to shore and is the most accessible to fishing. Several static protections (i.e., protections that are not based on a season or level of fishing effort) exist or have been proposed in the NCSM under the MSA (Supplementary Figure 1 and Supplementary Table 1). Taking the gear-specific protections for particular areas into account (Supplementary Table 1), President Trump's proclamation opens large portions of the NCSM canyons unit to commercial fishing (Figure 1B): $100 \%$ to pelagic gear (hook and line, purse seine, midwater trawls, and longlines), 59\% to bottom tending mobile gear (trawl, dredge, and seine), and 69\% to bottom tending fixed gear (traps/pots, set gillnets, and longline). If we consider the entire NCSM, $100 \%$ remains open to pelagic gear, but less area is open to bottom tending mobile and fixed gear (11 and 13\%, respectively) because the seamounts unit is fully protected from this gear.

Pelagic fishing gear and bottom tending fixed fishing gear represent a bycatch and entanglement risk for marine mammals (Moore et al., 2009; Henry et al., 2021; Josephson et al., 2021). Species that have been impacted by pelagic gear (NOAA, 2020a) occur in the NCSM: fin whale (Balaenoptera physalus), humpback whale (Megaptera novaeangliae), short-finned and long-finned pilot whales (Globicephala macrorhynchus and Globicephala melas), bottlenose dolphin (Tursiops truncatus), Risso's dolphin (Grampus griseus), common dolphin (Delphinus delphis), Cuvier's beaked whale (Ziphius cavirostris), and Mesoplodon beaked whales (Mesoplodon densirostris, bidens, and mirus). All marine mammals are protected by the Marine Mammal Protection Act and fin whales are listed as endangered under the Endangered Species Act (ESA). The policy change caused by President Trump's proclamation increases entanglement and bycatch risk for these species in the NCSM.

We used aerial survey data collected systematically from 2017 to 2020 to calculate encounter rates (number of animals per kilometer of survey effort) for cetaceans in regions of the canyons unit that are open versus closed to bottom tending fixed gear (Figure 1C and Supplementary Table 2). Although we use all available recent aerial survey data for these analyses, samples sizes are small for a number of species (Supplementary Table 2). Encounter rates for blue (Balaenoptera musculus), fin, humpback, and sei (B. borealis) whales, which feed primarily on krill and small schooling fish, were higher in areas that are open to fishing with bottom tending fixed gear. The same was true for common, Atlantic spotted (Stenella frontalis), and bottlenose dolphins, which are generalist feeders. However, striped dolphin (Stenella coeruleoalba), which are also generalist feeders, encounter rates were higher in areas protected from bottom tending fixed gear. Encounter rates were also higher in protected areas for species that feed primarily on squid, including Cuvier's, Sowerby's, and True's beaked whales, sperm whales (Physeter macrocephalus), pilot whales, and Risso's dolphins (Figure 1D). Consequently, the fisheries management measures reduce the risk of bycatch and entanglement for those species that feed on squid.

While similar data are not available to estimate specific changes in protections for seabirds and sea turtles, fishing in the NCSM will expose them to higher bycatch and entanglement risk (Moore et al., 2009). Species that have been impacted by bottom tending fixed gear (Benaka et al., 2019; Savoca et al., 2020) have been observed in the NCSM region prior to or after designation (eBird, 2020; Powers, 1983; Shoop and Kenney, 1992; Fayet et al., 2017): double-crested cormorant (Phalacrocorax auritus), common loon (Gavia immer), Atlantic puffin (Fratercula arctica), great shearwater (Puffinus gravis), northern gannet (Morus bassanus), herring gull (Larus argentatus smithsonianus), common murre (Uria aalge), sooty shearwater (Puffinus griseus), northern fulmar (Fulmarus glacialis), great black-backed gull (Larus marinus), loggerhead sea turtle (Caretta 
caretta), and leatherback sea turtle (Dermochelys coriacea). Both turtle species are listed as threatened under the ESA.

Increased bycatch and entanglement risk to marine mammals, seabirds, and sea turtles, represent protections lost at the sea surface and in the mid-water environment (Moore et al., 2009). The loss of these protections will also impact bycatch of elasmobranchs (including skates and pelagic/coastal sharks) and fish species (Supplementary Table 3). Several species that have essential fish habitat (EFH) that overlaps with the NCSM (we use EFH as an indication of possible presence in the NCSM) are overfished (NOAA, 2020b) and are listed as Endangered or Vulnerable on the International Union for Conservation of Nature Red List of Threatened Species: shortfin mako (Isurus oxyrinchus), dusky shark (Carcharhinus obscurus), Atlantic halibut (Hippoglossus hippoglossus), Atlantic cod (Gadus morhua), bigeye tuna (Thunnus obesus), bluefish (Pomatomus saltatrix), blue marlin (Makaira nigricans), porbeagle (Lamna nasus), white marlin (Kajikia albida), and yellowtail flounder (Limanda ferruginea). This list represents a minimum number of fish species potentially impacted by the loss of protections because it does not include species for which there are not enough data to determine their fishing or conservation status.

Finally, opening the monument to fishing with bottom tending fixed gear will impact seafloor species through bycatch and habitat destruction (Clark et al., 2016; Packer et al., 2017). In the NCSM, seafloor diversity hotspots have been identified and include deep-sea corals (Figure 1E), sponges, and fish (Auster et al., 2020). Little is known about the absolute abundance of these species because it is logistically challenging and expensive to conduct population status surveys in the deep sea. Consequently, we used an ensemble of results from a habitat suitability model for deep-sea gorgonian and non-gorgonian soft corals in waters off the Northeastern United States (NEFMC, 2019; Kinlan et al., 2020) as an indication of the change in protections experienced by seafloor species. We overlaid model predictions with the area that would be protected by the proposed Omnibus Deep-Sea Coral Amendment (i.e., $600 \mathrm{~m}$ isobath). We did not include the Lydonia and Oceanographer Canyons Gear Restricted Areas because these areas do not exclude bottom tending fixed gear. We found that $36 \%$ of the region predicted to have the highest habitat suitability for soft corals within the NCSM is unprotected (Figure 1F). The Omnibus exempts red crab fishing from depth restrictions and the trap gear used to catch red crabs can impact deep-sea corals. Red crab fishing currently occurs in waters up to $800 \mathrm{~m}$ deep (Wahle et al., 2008). Using the $800 \mathrm{~m}$ isobath to indicate where fishing can occur increases the area of unprotected soft coral habitat to $46 \%$.

\section{DISCUSSION}

The NCSM was designated a marine monument because of its unique ecological resources (e.g., high habitat and community diversity, high species richness, and ecological connectivity) that are of scientific interest. The original proclamation ultimately excludes all commercial-scale extractive activities within the NCSM. Our case study in the NCSM demonstrates that the fishing activities allowed by the MSA increase the risk of entanglement, bycatch, and habitat destruction for species from the sea surface to sea floor.

Fishing with pelagic gear exposes species inhabiting the sea surface and midwater regions to entanglement and bycatch risk throughout the entire NCSM. Fishing with bottom tending fixed gear exposes these species to entanglement and bycatch risk in over $50 \%$ of the canyons unit. They may also face declines in prey resources because the NCSM contains many species that are important prey (e.g., squid, mackerel, and butterfish) for higher level predators (e.g., marine mammals, seabirds, sharks, billfish, and tunas) and are also targeted by fisheries (as reviewed in Auster et al., 2020). Mothers with calves have been observed for many odontocete species in the NCSM (Figure 1D). Nursing mothers have high energetic requirements and may be particularly vulnerable to a reduction in prey resources. The NCSM also supports a high diversity of beaked whale species, which are sensitive to human disturbance (Southall et al., 2019). Fishing with bottom tending fixed gear exposes more than a third of potentially important deep-sea coral habitat to gear known to have detrimental impacts on these species. Additionally, any protections afforded under the MSA may be changed by Fisheries Management Councils and do not exist in perpetuity.

Fisheries management is not a substitute for a monument designation in the NCSM because opening the NCSM to commercial fishing has the potential to add bycatch and entanglement risk to the objects of scientific interest that the monument was designated to protect. The issue of the best policies to protect important marine habitats is not limited to the NCSM in the Atlantic Ocean. Monument designations by United States presidents from both political parties in the Pacific Ocean are facing similar challenges. In European waters, fishing inside MPAs has been found to jeopardize biodiversity conservation (Dureuil et al., 2018). Globally, almost all MPAs permit fishing (Costello and Ballantine, 2015). Marine protected areas range from multiuse areas, such as National Marine Sanctuaries in the United States, to areas that are highly protected from human impacts, such as United States marine national monuments. Protection strategies that depend on fisheries management compromise species protections. Our ocean is changing rapidly in response to industrialization and human driven changes to the Earth's climate. Highly protected marine areas help the broader ecosystem and adjacent commercial fisheries become more resilient to future ocean conditions.

\section{DATA AVAILABILITY STATEMENT}

Publicly available datasets were analyzed in this study. This data can be found here: Marine mammal data are available from the North Atlantic Right Whale Consortium: https://www.narwc. org/accessing-narwc-data.html. Protected area boundaries were obtained from the New England Fishery Management Council.

\section{AUTHOR CONTRIBUTIONS}

JR, KK, SK, and PA contributed to the conceptualization. JR, OO, EQ-R, and SK contributed to the data curation and funding acquisition. EQ-R and OO led the marine mammal aerial surveys. 
JR, LW, BH, and PA contributed to analyses. All authors contributed to the writing of the manuscript.

\section{FUNDING}

Aerial surveys were funded by the Conservation Law Foundation, National Ocean Protection Coalition, and Natural Resources Defense Council.

\section{ACKNOWLEDGMENTS}

We appreciate reviews of this manuscript by John Mandelman. Aerial surveys would not have been

\section{REFERENCES}

Auster, P. J., Hodge, B. C., McKee, M. P., and Kraus, S. D. (2020). A scientific basis for designation of the northeast canyons and seamounts marine national monument. Front. Mar. Sci. 7:566. doi: 10.3389/fmars.2020.00566

Benaka, L. R., Bullock, D., Hoover, A. L., and Olsen, N. A. (2019). US National Bycatch Report First Edition Update 3. NOAA Technical Memorandum NMFSF/SPO-190. Washington, DC: NOAA.

Clark, M. R., Althaus, F., Schlacher, T. A., Williams, A., Bowden, D. A., and Rowden, A. A. (2016). The impacts of deep-sea fisheries on benthic communities: a review. ICES J. Mar. Sci. 73(Suppl. 1), i51-i69.

Costello, M. J., and Ballantine, B. (2015). Biodiversity conservation should focus on no-take Marine Reserves: $94 \%$ of Marine Protected Areas allow fishing. Trends Ecol. Evol. 30, 507-509. doi: 10.1016/j.tree.2015.06.011

Dureuil, M., Boerder, K., Burnett, K. A., Froese, R., and Worm, B. (2018). Elevated trawling inside protected areas undermines conservation outcomes in a global fishing hot spot. Science 362, 1403-1407. doi: 10.1126/science.aau0561

eBird (2020). "eBird hotspot, oceanographer canyon," in eBird: An Online Database of Bird Distribution and Abundance [Web Application], (Ithaca, NY: eBird, Cornell Lab of Ornithology). Available online at: https://ebird.org/hotspot/ L1740213 (accessed October 3, 2020).

Fayet, A. L., Freeman, R., Anker-Nilssen, T., Diamond, A., Erikstad, K. E., Fifield, D., et al. (2017). Ocean-wide drivers of migration strategies and their influence on population breeding performance in a declining seabird. Curr. Biol. 27, 3871-3878.e3. doi: 10.1016/j.cub.2017.11.009

Henry, A. G., Garron, M., Morin, D., Smith, A., Reid, A., Ledwell, W., et al. (2021). Serious Injury and Mortality Determinations for Baleen Whale Stocks Along the Gulf of Mexico, United States East Coast, and Atlantic Canadian Provinces, 2014-2018. US Department of Commerce, Northeast Fisheries Science Center Reference Document 21-07. Washington, DC: US Department of Commerce.

Josephson, E., Wenzel, F., and Lyssikatos, M. C. (2021). Serious Injury Determinations for Small Cetaceans and Pinnipeds Caught in Commercial Fisheries off the Northeast US coast, 2014-2018. US Department of Commerce, Northeast Fisheries Science Center Reference Document 21-04. Washington, DC: US Department of Commerce.

Kinlan, B. P., Poti, M., Drohan, A. F., Packer, D. B., Dorfman, D. S., and Nizinski, M. S. (2020). Predictive modeling of suitable habitat for deep-sea corals offshore the Northeast United States. Deep Sea Res. Part I Oceanogr. Res. Pap. 158:103229. doi: 10.1016/j.dsr.2020.103229

Moore, J. E., Wallace, B. P., Lewison, R. L., Žydelis, R., Cox, T. M., and Crowder, L. B. (2009). A review of marine mammal, sea turtle and seabird bycatch in USA fisheries and the role of policy in shaping management. Mar. Policy 33, 435-451. doi: 10.1016/j.marpol.2008.09.003

Morato, T., Watson, R., Pitcher, T. J., and Pauly, D. (2006). Fishing down the deep. Fish Fish. 7, 24-34. doi: 10.1111/j.1467-2979.2006.00205.x

NEFMC, (2019). Omnibus Deep-Sea Coral Amendment, Appendix B: Coral Zone Boundary Development. Newburyport, MA: New England Fishery Management Council. possible without Avwatch and the observers, particularly Laura Ganley, Marianna Hagbloom, Katherine Mckenna, and Paul Nagelkirk. The base maps used in the figures were provided by NOAA OCS, ESRI, DeLorme, and NaturalVue. The deepsea coral habitat predictions were provided by the New England Fishery Management Council.

\section{SUPPLEMENTARY MATERIAL}

The Supplementary Material for this article can be found online at: https://www.frontiersin.org/articles/10.3389/fmars. 2021.645314/full\#supplementary-material

NOAA, (2020a). Federal Register. 50 CFR Part 229. Docket No. 200327-0090. RIN 0648-BI76. List of Fisheries for 2020 85, 21079-21103. Washington, DC: NOAA.

NOAA, (2020b). Second Quarter 2020 Update Summary of Stock Status for FSSI and non-FSSI stocks. Available online at: https://www.fisheries.noaa.gov/national/ population-assessments/fishery-stock-status-updates\#2020-quarterly-updates (accessed October 21, 2020).

Packer, D. B., Nizinski, M. S., Bachman, M. S., Drohan, A. F., Poti, M., and Kinlan, B. P. (2017). "State of deep-sea coral and sponge ecosystems of the Northeast United States," in The State of Deep-Sea Coral and Sponge Ecosystems of the United States. NOAA Technical Memorandum NMFS-OHC-4, eds T. F. Hourigan, P. J. Etnoyer, and S. D. Cairns, (Silver Spring, MD: NOAA), 35 .

Powers, K. D. (1983). Pelagic distributions of marine birds off the northeastern United States. NOAA Technical Memorandum NMFS-F/NEC-27. Washington, DC: NOAA.

Savoca, M. S., Brodie, S., Welch, H., Hoover, A., Benaka, L. R., Bograd, S. J., et al. (2020). Comprehensive bycatch assessment in US fisheries for prioritizing management. Nat. Sustain. 3, 472-480. doi: 10.1038/s41893-020-0506-9

Shoop, C. R., and Kenney, R. D. (1992). Seasonal distributions and abundances of loggerhead and leatherback sea turtles in waters of the Northeastern United States. Herpetol. Monogr. 6, 43-67. doi: 10.2307/1466961

Southall, B. L., Benoit-Bird, K. J., Moline, M. A., and Moretti, D. (2019). Quantifying deep-sea predator-prey dynamics: implications of biological heterogeneity for beaked whale conservation. J. Appl. Ecol. 56, 1040-1049. doi: 10.1111/1365-2664.13334

Trump, D. J. (2020). Proclamation on modifying the Northeast Canyons And Seamounts Marine National Monument. Available online at: https://www.whitehouse.gov/presidential-actions/proclamation-modifyingnortheast-canyons-seamounts-marine-national-monument/ (accessed July 2020).

Wahle, R. A., Bergeron, C. E., Chute, A. S., Jacobson, L. D., and Chen, Y. (2008). The Northwest Atlantic deep-sea red crab (Chaceon quinquedens) population before and after the onset of harvesting. ICES J. Mar. Sci. 65, 862-872. doi: 10.1093/icesjms/fsn058

Conflict of Interest: PA, SK, and OO are standing declarants for groups who have filed complaints in Federal court regarding the Trump proclamation.

The remaining authors declare that the research was conducted in the absence of any commercial or financial relationships that could be construed as a potential conflict of interest.

Copyright (c) 2021 Redfern, Kryc, Weiss, Hodge, O’Brien, Kraus, Quintana-Rizzo and Auster. This is an open-access article distributed under the terms of the Creative Commons Attribution License (CC BY). The use, distribution or reproduction in other forums is permitted, provided the original author(s) and the copyright owner(s) are credited and that the original publication in this journal is cited, in accordance with accepted academic practice. No use, distribution or reproduction is permitted which does not comply with these terms. 